\title{
IoT Things based Power Theft Analyzer \& Detection
}

\author{
Mahadev A. Gawas \\ Department of Electrical Engineering \\ Annasaheb Dange College of Engineering and Technology, \\ Ashta, India \\ Pradnya P. Wale \\ Department of Electrical Engineering \\ Annasaheb Dange College of Engineering and Technology, \\ Ashta, India
}

\author{
Rushikesh P. Gavade \\ Department of Electrical Engineering \\ Annasaheb Dange College of Engineering and Technology, \\ Ashta, India \\ Saniya J. Mujawar \\ Department of Electrical Engineering \\ Annasaheb Dange College of Engineering and Technology, \\ Ashta, India
}

\author{
Prashant S. Mali \\ Department of Electrical Engineering \\ Annasaheb Dange College of Engineering and Technology,
}

Ashta, India

\begin{abstract}
Today world is facing major problem in power system network is power theft. Theft of electricity is a criminal act and due to these power utilities losing millions of rupees. Internet of Things (IoT) connects sensing devices to the internet for the purpose of exchanging data rapidly. The aim of this is to design implementation model of electrical energy theft detection without human interaction. The purpose of this framework is to reduce the energy theft cases and accidents occurs due to the power theft. It includes Particle photon board which is completely hardware kit based embedded technology and wireless communication method to find out the electric theft and distribution line fault. Particle photon is powerful IoT prototyping platform. The particle photon has numbers of advantages like remote programming, easy code transfer and fast turn ON of projects. The main part of photon is that it has fast processor, plenty of memory and inbuilt WiFi. The proposed system with particle photon will be efficient and alternate for Arduino and Embedded based data processing. Photon will overcome the existing drawbacks and response quickly without any delay. The target of the proposed framework is to give proper solution to the theft problem and to reduce the efforts of the human.
\end{abstract}

Keywords - Internet of Things(IoT), Power theft, Particle Photon, Graphical user interface (GUI).

\section{INTRODUCTION}

Electricity theft can be defined as "an illegal usage of electricity equipment or service with the intention to avoid billing charges". Electrical Power theft is a major problem in power system network which is illegal and strictly prohibited. Electricity theft is the main problem faced by power utilities all over the world. Practice of electricity pilferages is considered as illegal and as a crime [1-2]. There are many types of electricity theft like tampering the meter, whole meter bypassing, showing low meter reading, billing irregularities and unpaid bills [3-5]. Some customers try to take out the meter from their system so that no reading will be recorded in the meter even though the electricity in the home is being used [6-7].

Power theft causes major impact on electricity system and institutions- a) theft of electricity results in loss of revenue to the utility / institution,

b) leading to overloading of transformer creating blackouts or brownouts because of the undesirable load on transformers,

c) damage to property of the utility such as distribution transformer, protective devices etc. and d) increase in transmission and distribution losses due to tampering of wires and cables.

\section{PROPOSED BLOCK DAIGRAM}

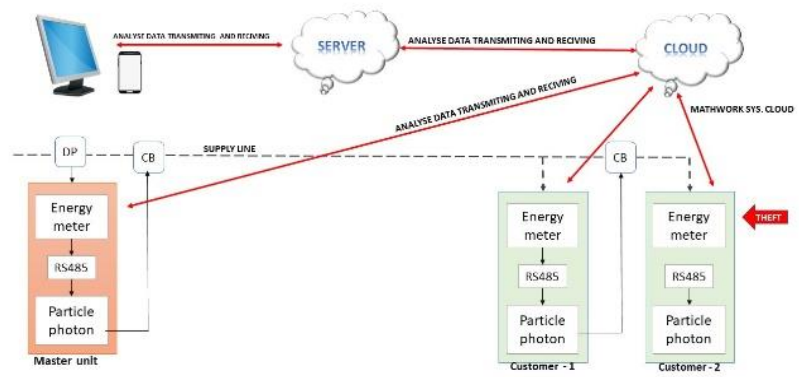

Fig. 1 Proposed Block Daigram

A. Monitoring unit:

In the block diagram we have a monitoring unit at the leftmost side. Monitoring unit consists of monitoring devices such as computer, mobile, controller etc. We receive data of each and every instant at this monitor and in line with the data present at monitor unit. we can control or monitor our system. We can take action according to the data received, as monitor unit are connected to each other for data transfer.

\section{B. Server:}

A server is said to be a computer which is designed to process request and also to deliver data to any other computer over internet, a local area network or wide area network. Mostly the word server means web server with which the web pages can be accessed over internet through clients like web browsers. 


\section{Cloud Storage:}

Cloud storage is a cloud computing model which provide data storage options without direct active management by users. We need to store the data present in our system for which we use cloud storage. Since we are using mathworks cloud storage, we are given choices to create a channel on which our data will be continuously updated, monitored and can be accessed any time.

\section{Master unit:}

Master unit is the unit present at the supply side of the load, it is placed near the distribution board. Master unit consists of

\section{E. a) Energy meter-} three subparts that are:

This energy meter takes the readings of supply side and these are used to find out the theft occurring if any. This energy meter is further interfaced with RS485.

\section{b) $R s 485-R S 485$}

It is usually used for serial communication purpose. RS485 helps to take data from energy meter serially and give it to particle photon

\section{c) Particle Photon-}

Particle Photon can be called as a heart of this project model as without this we cannot take the control actions. Particle photon works as a controller and is must to action remotely whenever power theft occurs.

\section{d) Unit 1 and 2:}

Unit 1 and 2 represent the customer side. Unit 1 and 2 have identical subparts like master unit. As the data of supply side is made available by the master unit, in the same way the data of customer side is made available by these units.

\section{Comparison Of Old AND New Model}

The proposed system is to detect and monitor the theft of electricity by using PLC. In this area of electricity consumers is divided into sections and for each section IoT based Energy meter is installed to monitor all the parameter of the sections. And one master unit is provided at near distribution pole site to monitor all the sections data.

To show the all the parameters of the system we are going to use Think Speak website to display all the parameters in graphically well as digit format. Here at the Think Speak site MATLAB simulation and visualization is provided to analyze data. At every time interval all the data of the systems is automatically stored in one excel sheet so there is no need to write $\&$ note any readings.

When someone hooks the line in any section, data of all the sections is stored in Think Speak cloud and data get analyzed. In this analyzing process the master unit data is compared with the sum of all sections data and if both the data gets matched it means the there is no any theft. And if there is theft condition available both data did not get matched and Think Speak shows theft condition on website page and RED indicator and alarm gets turned on. Previous systems have some limitations like some systems take more time, some of the units are Arduino and Embedded based. Data processing is limited but by using PLC all those drawbacks get overcame and system response becomes fast.

\section{A. WEB Page:}

This system can be used to display load consumed in watts, current, frequency and the system status in the indicator format (to show energy theft condition). This system is able to access information from anywhere worldwide. Webpage which takes the help of the MathWork MATLAB analysis to display the all information and also for analysis purpose. Online MATLAB simulation is also provided at this site for simulation purpose. All the information we can fed into the $8^{\text {th }}$ different fields. The analysis can be visible to the consumer as well as the service provider

\section{METHODOLOGY}

The structure of the system is working with following steps: A] All the Particle Photon Board connected to internet using WiFi.

B] Multi-Functional meters sensed the data and send data to the cloud with the help of Particle Photon Board.

C] All the readings are displayed in the cloud and shows in the graphical format in charts.

D] Cloud finds the difference in the readings by subtraction method. (Sending end Power - Consumed Power)

E] If any error found in Step-D above the predetermine level then system conditions get changes.

F] System status become RED in indicator Charts. It means energy theft is occurring in the system and all the theft system parameter is shows in the Theft chart in graphically format and sounds Alarm.

G] Then cloud send command circuit breaker to open the contacts and interrupt the power flow in the system (this step is occurs only if administrator wants to interrupt the energy only if energy theft is occurring in system).

A. Flowchart:

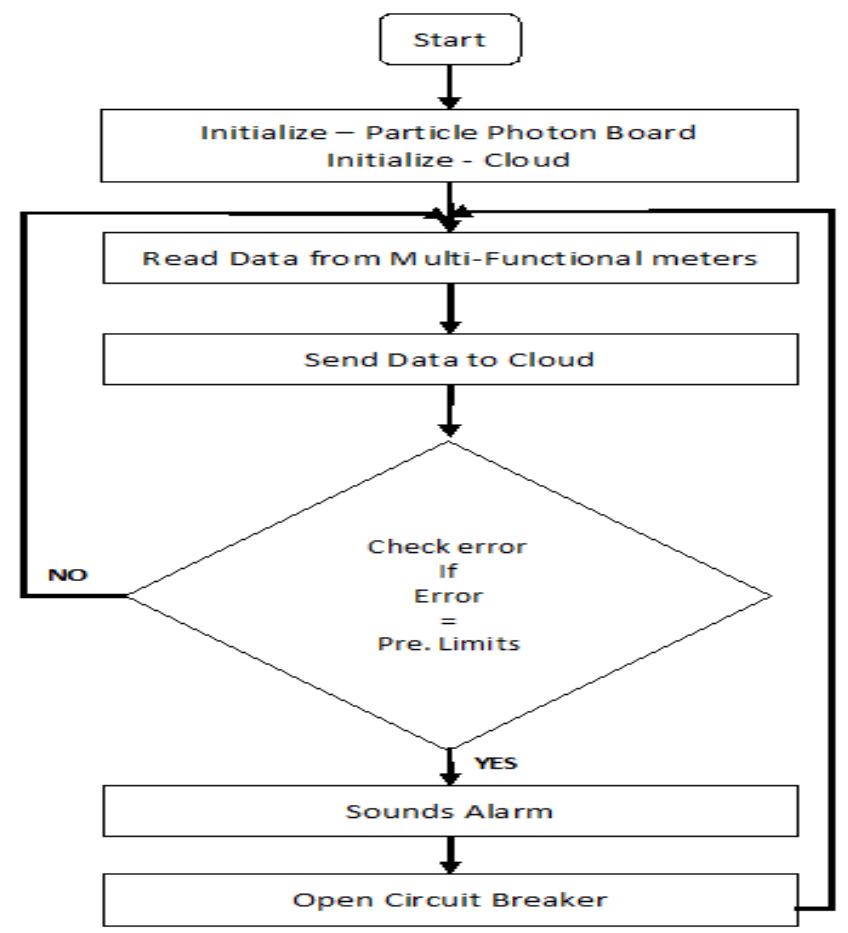




\section{RESULTS, APPLICATION AND FUTURE SCOPE}

\section{A. Results:}

First we have to start the system and connect to the network. When the consumer starts the power consumption the multifunctional meters sensed the power utilized by the load. The particle photon board is connected to the serial serial communication port (RS485) of Multifunctional Meters. The digital output of the multifunctional meters is shown in the Image-1.

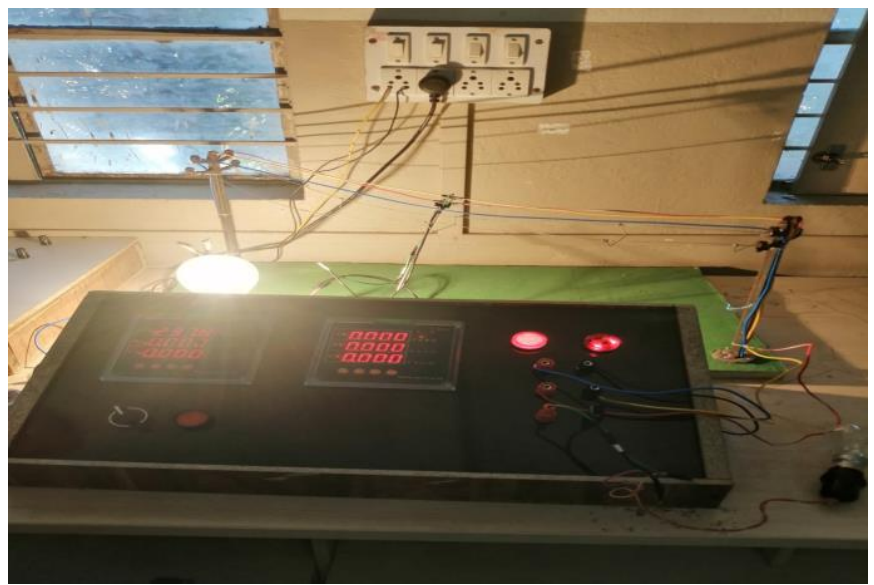

Image-1: Actual hardware during power consumption measurement.

The particle photon board is connected to internet with the system. And all the parameters of the system are displayed in the cloud viz. ThinkSpeak cloud in graphical format. Chart-1 and Chart- 2 below. Its shows the time to time system condition and all the parameters of the system in charts format
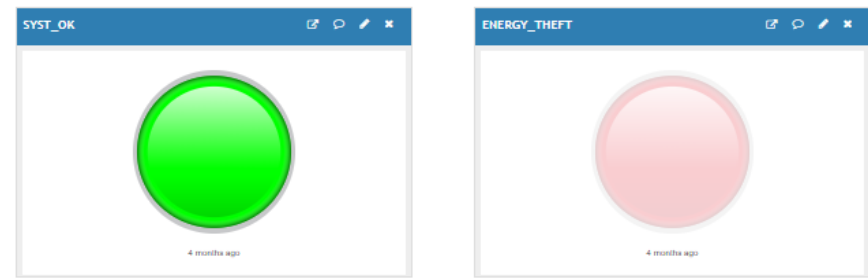

Chart-1: System condition indicators $(\mathrm{RED}=\mathrm{Theft})$

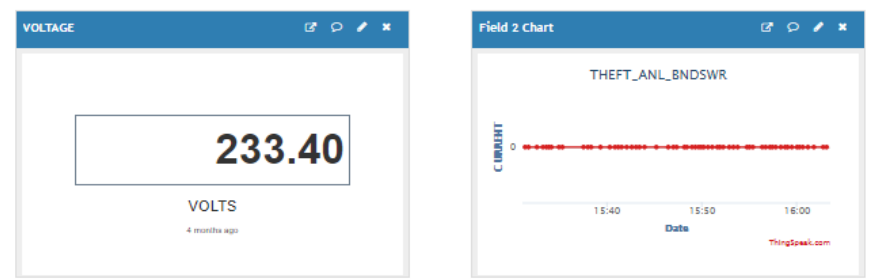

Chart-2: System parameters on webpage GUI

\section{B. Future Scope:}

This basic system we can upgrade to a great level by introducing the GPS module in system. If we introduced the GPS in system, then it will be become easy to identify the perfect energy theft area. Thing Speak cloud is also provides the Map in their charts to display the locations of system. So to improve the performance of the system more efficiently we have to connect GPS module to Particle photon board and location we have to send on cloud location chart.
C. Application:

- Real time power monitoring of any system (like Domestic and industrial loads)

- System is incorporated with all kind of users

- Idea is well suited for energy theft properly, especially for rural and city areas

- It is also possible to implement in school and colleges for power monitoring purpose

- It is easy to analyze the amount of energy theft in system or in Area

\section{CONCLUSION}

In this paper, Energy theft monitoring using IoT is an innovative application of internet of things developed to control the power theft remotely over the cloud from anywhere in the world. In the proposed project particle photon module used for monitoring purpose. The system updates the information in every 10 to 12 seconds on the Think Speak cloud using internet. This system is basically made for the reduce the Electricity theft (or pilferage) issue to reduce the commercial losses, direct hooking on power line this issues can be also eliminated by using this system.

\section{REFERENCES}

[1] Control Of Electricity Theft Using Arm Based Prepaid Metering System And Gsm Module B.Manisha Sanghamitra, S.Krithiga, Electronics And Communication Engineering, Srm University, (India).

[2] Electricity Theft Detection Techniques For Metered Power Consumer In Guvnl,Gujarat,India Bharat Dangar Electrical Engg Dept., The M.S.University Of Baroda, Vadodara, Gujarat, India.

[3] Embedded Prepaid Energy Meter System To Control Electricity Mohammed Ibrahim Hussain1, Dr. S. Sivasubramanian21, 2cse Department, Mohamed Sathak A.J College Of Engineering.

[4] Wireless Power Theft Detection And Intimation System By Using Gsm A. A.Suryawanshi Professor, Dept. Of Ee, Sitcoe, Yadrav, India Varsha Shinde, Priyanka Pol, Priyanka Chavan, Shraddha Bhui, And Supriya Omase Department Of Ee, Sitcoe, Yadrav, Tal: Shirol Dist. Kolhapur, India.

[5] A Review On Iot Based Power Theft Detection And Control Systems Harsha Khandel, Suchitra Pandey, D. Reynolds Dept. Of Electronics Engineering, Bit, Durg, C.G, India.

[6] Wireless Power Theft Monitoring Systemm Sai Supriya G K , Priyamvadaa R, Savita Sangappa Mulimani Department Of E\&C(Dec), Dayananda Sagar College For Pg-Studies, Bengaluru, India.

[7] Iot Based Smart Energy Monitoring Abhiraj Prashant Hiwale, Deepak Sudam Gaikwad, Akshay Ashok Dongare, Prathmesh Chandrakant Mhatre, Dilkap College, Neral, Maharashtra, India. 